九州大学学術情報リポジトリ

Kyushu University Institutional Repository

Effect of Geomorphological Factors of Small Catchments on Peak Discharge at Confluence Points

Kasai, Mio

Soil and Water Conservation Laboratory, Faculty of Agriculture, Kyushu University

Fujino, Takako

Laboratory of Silviculture, Faculty of Agriculture, Kyushu University

Marutani, Tomomi

Soil and Water Conservation Laboratory, Faculty of Agriculture, Kyushu University

https://doi.org/10.5109/24083

出版情報：九州大学大学院農学研究院紀要. 39 (3/4)，pp.221-227，1995-03. Kyushu University バージョン：

権利関係 : 


\title{
E ffect of Geomorphological Factors of Small Catchments on Peak Discharge at Confluence Points
}

\author{
M io Kasai, Takako Fujino* and Tomomi Marutani \\ Soil and Water Conservation Laboratory, \\ Faculty of Agriculture, Kyushu University 812-81, Japan \\ (Received November 29, 1994)
}

\begin{abstract}
Effect of geomorphological factors of small branch catchments on the peak discharge of a main channel at confluence points was analyzed from the observation of discharge and the measurement of geomorphology. Catchment area, catchment shape, channel gradient, bifurcation ratio and length ratio of branch catchments were acquired from 1/25000 topographical map. A hydrograph appeared during a flood changed according to the catchment shape, represented by the bifurcation ratio and the length ratio. The effect of the channel gradient on the discharge was little in small catchments (from $0.859 \mathrm{~km}^{2}$ to $0.945 \mathrm{~km}^{2}$ in area). A sum of peak values of discharge of branch catchments equaled to a peak value of discharge in main channel. Peaks in the hydrography curve of branch catchments often coincided to those of main channel. In the case that confluence points departed about $300 \mathrm{~m}$ in distance, the peaks disappeared in the hydrography curve.
\end{abstract}

\section{INTRODUCTION}

Temporal changes of flood discharge, determined by rainfall intensity, catchment area, channel gradient and runoff rate, are generally demonstrated as a hydrography curve with one peak during a continuous rainfall.

However the discharge of a small catchment where we observed were not fitted to the hydrography curve with one peak. According to our observation, some peaks were included in the curve during a continuous rainfall. Such a curve was shown, even if catchment area, rainfall intensity and runoff rate of each catchment were same. Temporal changes of flood discharge are differed by the catchment shape and the rainfall area, and the number of peaks of discharge spatially affected by the confluences of branch channels (Knapp, 1979 ;Kirkby, 1978).

Geomorphology of small catchments along branch channels can be also effective on temporal and spatial changes of discharge. Especially at the lower reaches of confluence points, the peak discharge may often show large value in a moment. The small catchments about $10^{-1}$ to $10^{-4} \mathrm{~km}^{2}$ in area were recognized as debris-flow -dominated channel owing to local steepness in gradient (Montgomery, 1993). At the reaches of local steep channels in gradient, the sediment transport power radically increase at the peak of discharge.

We analyzed the effect of geomorphological factors of small catchments in the peak discharge of hydrograph based on catchment shape, bifurcation ratio and length ratio along the branch channels of small catchments.

\footnotetext{
* Laboratory of Silviculture, Faculty of Agriculture, Kyushu University 812-81.
} 


\section{METHOD}

The Oyabu river flows through a crasher zone crossing the Kyushu mountain range from north to south. Figure 1 shows the topography of the Oyabu river catchment and the gauging points of water levels. According to channel order by Horton-Strahler method (Strahler, 1952), the drainage network of the Oyabu river catchment consists of three channels of third order as the branch channels (Shikino -tani, Bouzu-dani, Kouchino-tani) and a fourth order channel as the main channel (the Oyabu river). In order to measure the changes of discharge in three branch channels, the float gauges were set up at each outlet of the catchment along the third order channel, and hydraulic pressure water gauge was equipped at the main channel lower from confluence point of Shikino-tani.

Flood discharge was analyzed by using the calibration data from water levels for six months (from April 1994 to September 1994) with automatic water gauges. As the cross sections at gauging points are regarded as rectangular section, water levels were calibrated into values of discharge as next equation. The flood discharge was analyzed for four days from 11 August to 14 August.

$$
Q=\mathrm{a}^{2}(H+\mathrm{a} / \mathrm{b})^{2} \text {. }
$$

Rearranging equation (1),

$$
Q^{1 / 2}=\mathrm{a} H+\mathrm{b}
$$

where $\mathrm{Q}$ is the discharge,

$H$ is the water level,

$a$ and $b$ are coefficients.

Coefficients a, b in eq. 2 were calculated by the least squares method.

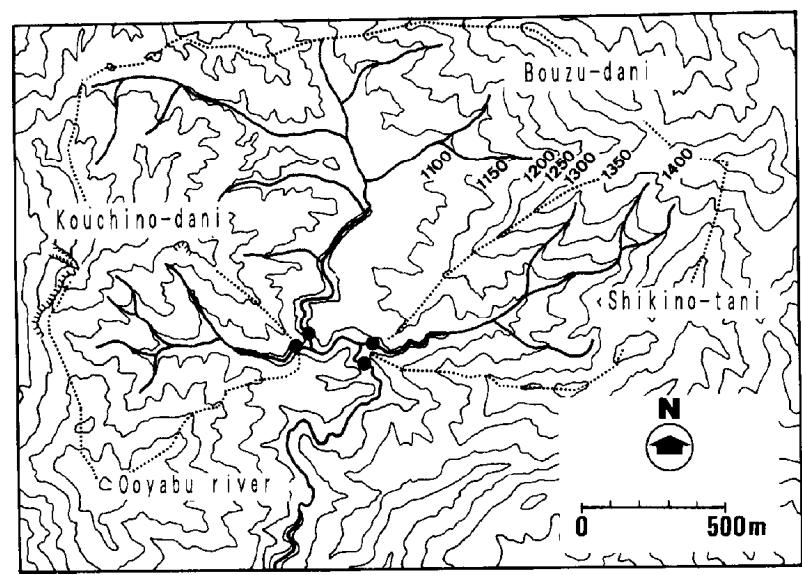

Fig. 1. Location map of Oyabu river catchment and measuring points of water level with automatic water gauges. 


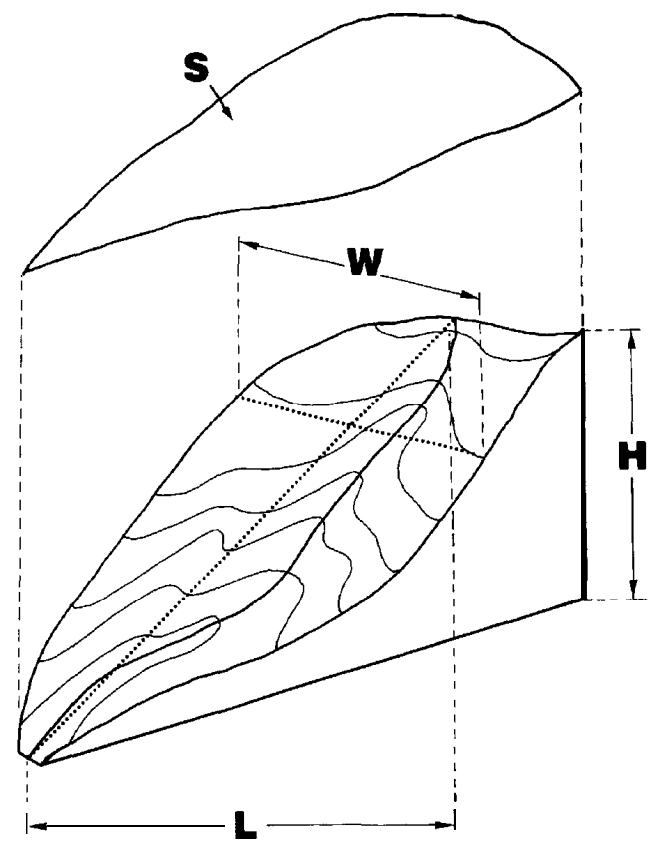

Fig. 2. Method of measuring geomorphology. $\mathrm{S}:$ Catchment area, $W / L$ : Catchment shape, $H / L$ : Channel gradient.

Geomorphology of each branch catchment of third order channel was analyzed. Catchment area, catchment shape, channel gradient, bifurcation ratio and length ratio by the Horton's law (Horton, 1945) were acquired from 1/25000 topographical map. The catchment area was measured by using a planimeter. The catchment shape was represented as the ratio of the longest horizontal distance of channel profile (from the outlet of a catchment to the top) and the longest horizontal distance of crossing toward it about third order channel. The channel gradient was represented as the ratio of the longest horizontal distance and the differential in altitude between the outlet of a catchment and the top (Fig. 2).

\section{ANALYSES}

Analyses of discharge

The discharge of three branch catchments (Bouzu-dani, Kouchino-dani and Shikino-tani) and a main catchment (the Oyabu river) temporally had changed during four days as shown in Fig. 3. Since the peak discharge of these catchments appeared approximately at the same time, they are called as the peak a, b, c, d and e by common. The total discharge of each catchment gives

$$
Q \mathrm{~m}(t) d t<Q \mathrm{~b}(t) d t<Q \mathrm{~s}(t) d t=Q \mathrm{k}(t) d t,
$$




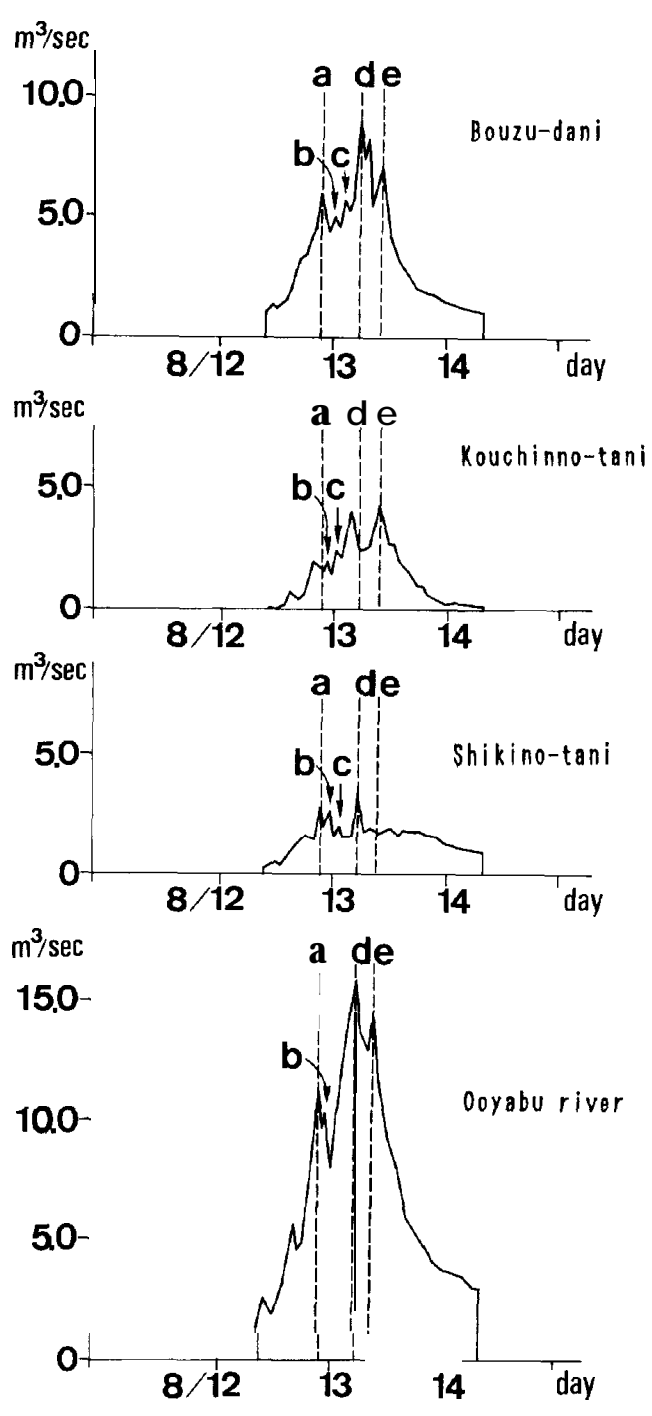

Fig. 3. Hydrograph of the flood discharge from 12 August to 14 August, 1994.

where $Q \mathrm{~m}(t)$ is the discharge of the Oyabu river at the time $t$,

$\mathrm{Qb}(t)$ is the discharge of Bouzu-dani at the time $t$,

$Q \mathrm{~s}(t)$ is the discharge of Shikino-tani at the time $t$,

$Q \mathrm{k}(t)$ is the discharge of Kouchino-dani at the time $t$.

The discharges of each catchment at the peak d, which is the highest peak during a continuous rainfall, is $\& \mathrm{~m}(\mathrm{~d})=15.67 \mathrm{~m}^{3} / \mathrm{sec}, Q \mathrm{~b}(\mathrm{~d})=9.00 \mathrm{~m}^{3} / \mathrm{sec}, \& \mathrm{k}(\mathrm{d})=3.14 \mathrm{~m}^{3} / \mathrm{sec}$ and $Q_{\mathrm{S}}(\mathrm{d})=3.42 \mathrm{~m}^{3} / \mathrm{sec}$ respectively, and related by 


$$
Q \mathrm{~m}(\mathrm{~d})=Q \mathrm{~b}(\mathrm{~d})+Q \mathrm{k}(\mathrm{d})+Q \mathrm{~s}(\mathrm{~d})
$$

The peak e of Shikino-tani appeared earliest of three branch catchments. The peaks a and d of Kouchino-tani came about 20 minutes earlier than the other catchments. The peak c appeared in Kouchino-tani, Bouzu-dani and Shikino-tani except of the Oyabu river.

\section{Analyses of geomorphology}

Catchment area, catchment shape, channel gradient, bifurcation ratio and length ratio of each catchment are showed in Table 1. The table gives

$$
\begin{gathered}
A \mathrm{~b}>A \mathrm{k}=A \mathrm{~s}, \\
S \mathrm{~b}<S \mathrm{k}<S \mathrm{~s}, \\
I \mathrm{~b}<I \mathrm{k}<I \mathrm{~s},
\end{gathered}
$$

where $A \mathrm{~b}$ is the catchment area of Bouzu-dani,

$A \mathrm{k}$ is the catchment area of Kouchino-tani,

As is the catchment area of Shikino-tani,

$\mathrm{Sb}$ is the catchment shape of Bouzu-dani,

$\mathrm{Sk}$ is the catchment shape of Kouchino-tani,

$S$ s is the catchment shape of Shikino-tani,

$I \mathrm{~b}$ is the channel gradient of Bouzu-dani,

$I \mathrm{k}$ is the channel gradient of Kouchino-tani,

Is is the channel gradient of Shikino-tani.

Considering with the Horton's first and second laws, these branch catchments more larger in the bifurcation ratio (from 4.25 to 6.00 ), but smaller in the length ratio (from 1.75 to 2.03 ) than common catchments. The bifurcation ratio and the length ratio of each catchment are related by

$$
\begin{gathered}
B \mathrm{k}>B \mathrm{~b}>B \mathrm{~s}, \\
L \mathrm{~b}<L \mathrm{k}=L \mathrm{~s},
\end{gathered}
$$

where $B \mathrm{k}$ is the bifurcation ratio of Kouchino-tani,

$\mathrm{Bb}$ is the bifurcation ratio of Bouzu-dani,

$B s$ is the bifurcation ratio of Shikino-tani,

$\mathrm{Lb}$ is the length ratio of Bouzu-dani,

$\mathrm{Lk}$ is the length ratio of Kouchino-tani,

$L s$ is the length ratio of Shikino-tani.

Table 1. Catchment area, catchment shape, channel gradient, bifurcation ratio and length ratio.

\begin{tabular}{l|ccc}
\hline & Kouchino-tani & Bouzu-dani & Shikino-tani \\
\hline Catchment area $\left(\times 10^{-2} \mathrm{~km}^{2}\right)$ & 85.9 & 256.6 & 94.5 \\
Catchment shape & 1.08 & 0.52 & 2.20 \\
Channel gradient & 0.09 & 0.04 & 0.12 \\
Bifurcatin ratio & 6.00 & 5.55 & 4.25 \\
Length ratio & 2.05 & 1.76 & 2.02
\end{tabular}




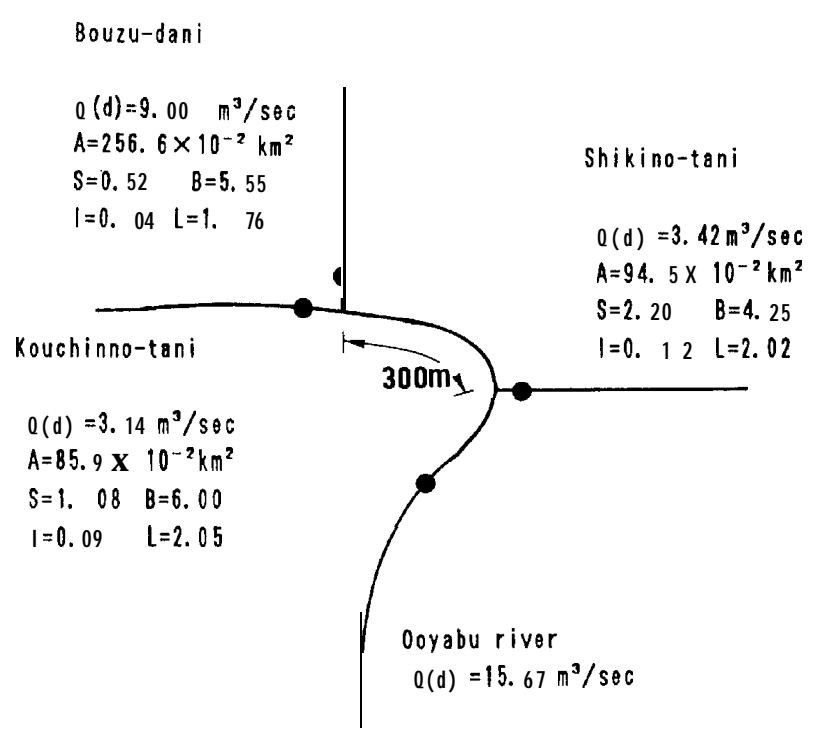

Fig. 4. Schematic river channel with confluens points. A : Catchment area, $S$ : Catchment shape, $B$ : bifurcation rate, $I$ : Channel gradient, $L$ : Length ratio.

The confluence points in study area and the values of $\boldsymbol{A}, S, \boldsymbol{I}, B$ and $L$ described above are illustrated in Fig. 4. Shikino-tani joins with the Oyabu river at the point of about $300 \mathrm{~m}$ downstream from the confluence point of Kouchino-tani and Bouzu-dani.

\section{RESULT AND DISCUSSION}

A changing range was defined as the differential between maximum and minimum of discharge during a continuous rainfall. The changing range during flood at Shikino -tani was small relatively to Kouchino-tani. Also the total discharge and the numbers of peaks of Shikino-tani were equal to them of Kouchino-tani.

In geomorphology, Shikino-tani was steep in the channel gradient, large in the catchment shape and small in the bifurcation ratio in comparison to Kouchino-tani samein the catchment area. The effect of the channel gradient on total discharge was expected to be little in the small catchments $\left(0.859 \mathrm{~km}^{2}\right.$ at Kouchino-tani and 0.945 $\mathrm{km}^{2}$ at Shikino-tani). The length ratio and the bifurcation ratio were controlled by the numbers of confluence points the branch catchments, Shikino-tani and Kouchino -tani. These ratio would be effective to the changing range of flood discharge.

At Bouzu-dani, the changing range was largest of three branches. The catchment area and the bifurcation ratio showed large values, nevertheless the catchment shape and the length ratio showed small values. As the value of the length ratio also is small, the channel length in longitudinal profile should to be short. Results from the analyses of geomorphology explained that the changing range of discharge become to be large value according to the small value of the catchment shape of Bouzu-dani. 
The total discharge of the Oyabu river was composed by these of three branch catchments (Fig. 4) in eq. 3. The discharge of the peak $\mathrm{d}$ can be calculated as the sum of discharge of the peak $d$ in hydrograph of three branch catchments in eq. 4. The peak c, which was shown in the hydrography curve of three branch catchments, was not appeared in that of the Oyabu river.

This seemed to be caused by the time lag of the peaks at Kouchino-tani and Bouzu -dani with the confluence. But the peak at Shikino-tani was not efficiency to appear the peak at the confluence point of the Oyabu river and Shikino-tani. These results lead that low peaks of hydrography curve were disappeared at a confluence point because of time lag of a peak at each catchment.

The changing range of discharge tend to be large at the catchment which has short in longitudinal profile along a branch channel. The catchment showed large value in bifurcation ratio and small value in length ratio. The time lag of a peak of hydrography curve will be expected to increase with adjacency of confluence points and decrease with distance of confluence points.

\section{ACKNOWLEDGEMENTS}

The field survey and the observatory maintenance in the Oyabu river owed to the contribution by Dr. K. Aragami, Dr. Y. Teraoka and the staff of Miyazaki Forest of Kyushu University. We would like to appreciate to all of them.

\section{REFERENCES}

Horton R. E. 1945 Erosional development of stream and their drainage basins-Hydrophysical approach to quantitative morphology-. Bull. G. S. A., 56: 275-330

Knapp B. 1979 Elements of Geographical Hydrology. George Allen and Unwin. London, pp. 17-21 Kirkby M. J. 1978 Hillslope Hydrology. Jon Wiley and Sons, London, pp. 203-252

Marutani T. and M. Kasai 1994 Geomorphological analyses of Oyabu river basin. Bull. Kyushu. Univ. For., in press

Montgomery D. R. and E. Foufouria-Georgiou 1993 Channel network source representation using digital elevation models. W.R.R. 29 (12) : 3925-3934

Strehler A. N. 1952 Hypsometric (area-altitude) analysis erosional topography. Bull.G. S. A., 63: 1117-1142 